\title{
Antibiotic use during pregnancy: a retrospective study of prescription patterns and birth outcomes at an antenatal clinic in rural Ghana
}

\author{
Kwesi Boadu Mensah*, Kwame Opoku-Agyeman and Charles Ansah
}

\begin{abstract}
Background: Babies are increasingly being exposed to antibiotics intrapartum in the bid to reduce neonatal and maternal deaths. Intrapartum antibiotic exposure, including even those considered safe in pregnancy, have been associated with childhood obesity and compromised immunity. Data on the extent of antibiotic use, safety and its impact on birth outcomes and neonatal health in Sub-Saharan Africa is very limited. This study sought to ascertain the extent of antibiotic use in pregnancy and its effects on birth outcomes in a rural hospital in Ghana.

Methods: The study was a retrospective randomized study of mothers who delivered babies in a rural hospital between 2011 and 2015 in Ghana. A total of 412 mother/baby records out of 2100 pre-selected met the inclusion criteria of the study. Indicators of neonatal health used were birthweight, Apgar score, incidence of birth defects.

Results: Sixty five percent of pregnant women were administered antibiotics at some stage during pregnancy. Beta Lactam antibiotics accounted for more than $67 \%$ of all antibiotics prescribed. There was a statistically significant association between antibiotic exposure and pregnancy factors such as stage of pregnancy, parity and mode of delivery but not with socio-economic status of the mother. Intrapartum antibiotic exposure did not significantly affect the birthweight, incidence of congenital birth defect and mean Apgar scores. After adjusting for method of delivery, however, perinatal antibiotic use (24 h to delivery) was associated with lower mean Apgar scores. Birth weight was affected significantly by maternal socio-economic factors such as age and marital status.

Conclusion: Sixty five percent of women attending the antenatal clinic received antibiotics. Intrapartum antibiotics did not affect early markers of neonatal health such as birthweight, congenital birth defect and mean Apgar scores. However, antibiotic use less than $24 \mathrm{~h}$ to delivery was associated with a decrease in mean APGAR score.
\end{abstract}

Keywords: Pregnancy, Birth outcomes, Congenital defects, APGAR scores, Antibiotic, Intrapartum, Birthweight

\section{Background}

There has been a sturdy increase in global antibiotic prescription and consumption [1]. Several concerns have been raised about irrational use of antibiotics and its subsequent impact on drug resistance and cost of healthcare. Furthermore, the role that human microbiota, believed to account for the greater part of human body weight, plays in programming the immunity and

\footnotetext{
* Correspondence: kbmensah.pharm@knust.edu.gh

Department of Pharmacology, Faculty of Pharmacy and Pharmaceutical

Science, Kwame Nkrumah University of Science and Technology, Kumasi, Ghana
}

(c) The Author(s). 2017 Open Access This article is distributed under the terms of the Creative Commons Attribution 4.0 International License (http://creativecommons.org/licenses/by/4.0/), which permits unrestricted use, distribution, and reproduction in any medium, provided you give appropriate credit to the original author(s) and the source, provide a link to the Creative Commons license, and indicate if changes were made. The Creative Commons Public Domain Dedication waiver (http://creativecommons.org/publicdomain/zero/1.0/) applies to the data made available in this article, unless otherwise stated.

metabolism of an individual has re-emphasized the need to regulate use of antibiotics [2].

Pregnancy presents with significant risk of complications which may lead to morbidity and mortality for mother-baby pairs. Globally, more than $50 \%$ of neonatal deaths occur in Sub-Saharan Africa because of infections and limited health resources [3, 4]. To manage the complications associated with pregnancy and motherhood, many medicines are employed. Antibiotics remain important in pregnancy and may be second to only iron and food supplement [5]. Due to limited health resources, such as laboratories to carry-out culture and 
sensitivity test, the extent of exposure of pregnant women and babies to antibiotics and the effects on their health may be underestimated.

There have been several attempts to promote rational antibiotic use partly because of the risk of drug resistance, increased cost of healthcare, as well as the risk of teratogenicity in the developing foetus [6, 7]. However, recent studies have shown that there may be other insidious risk associated with antibiotic use in pregnancy independent on safety profile, mechanism of action or even class the of antibiotic [2]. For instance it is well documented that Caesarian birth or intrapartum antibiotic exposure contributes adversely to childhood obesity and compromised immunity of the baby $[8,9]$. Unlike classical teratogenesis, these effects occur indirectly through alterations of the maternal microbiota without the agent necessarily crossing the placenta to affect the tissues of the foetus.

Neonatal Health and Birth outcome is highly dependent on maternal health, nutrition and socioeconomic factors. The use and choice of antibiotic during pregnancy depends primarily on maternal factors such as health, nutrition, mode of delivery and socioeconomic factors. These maternal factors influence the indicators used to estimate birth outcomes and neonatal health such as birth weight, APGAR scores, and incidences of birth defects. To able to understand the full extent and effects of intrapartum antibiotics on mother and babies, there is a need to elucidate the complex interplay between maternal health, mode of delivery and socio-economic status and neonatal health.

A key point in the millennium development goals is reducing maternal and neonatal mortality. To date there is little clinical data on the trends of antibiotic use during pregnancy and its effects on neonatal health from sub-Saharan Africa. Using Birth weight, APGAR scores, and incidences of birth defects as indicators of birth outcomes and early neonatal health and survival, this study examines the use of antibiotics during pregnancy, its effects on birth and neonatal health and as well as the effects of other maternal factors on antibiotic use in a rural health facility in Ghana.

\section{Methods}

\section{Study area}

Seventh-Day Adventist Hospital, Dominase is a 45 bed capacity hospital located in Dominase about $19 \mathrm{~km}$ off the Kumasi-Cape coast highway. The hospital has an obstetrics and gynaecology unit which runs an antenatal clinic with a resident gynaecologist, pharmacist and several midwives and nurses. To limit the impact of unprescribed and undocumented antibiotic usage, the area chosen was predominately rural with no existent pharmacy. Furthermore, the National Health Insurance
Scheme of Ghana runs a "capitation policy" where patients choose a particular primary health care facility for their needs without paying out of pocket. Patients who visit any other facility aside the allocated facility have to pay to access healthcare. This discouraged the tendency for mothers from seeking health services from other facilities as well as reduce self -medication. This is of particular importance because antibiotics can be obtained without prescription in Ghana.

\section{Study design}

The design was a retrospective descriptive study. The primary source of data was prescriptions generated and recorded in patient medical records filed in the hospital between January 2011 and December 2015.

\section{Sampling method}

Folder numbers of all live babies born in the hospital between January, 2011 and September, 2015 were retrieved from the registration book at the maternity unit. Five hundred folder numbers were selected for each of the 5 years from the registration book using systematic sample, making a total of 2500 folders. The contents of 2100 folders were available for the study. Each folder of mother-baby pairs was subsequently screened using the inclusion and exclusion criteria. A total of 412 motherbaby pairs met the selection criteria.

The Inclusion criteria included;

- The mother should have attended at least three ANC at the hospital after confirmation of pregnancy either by ultrasonography or Human Chorionic Gonadotrophic (HCG) detection method.

- Should have delivered a live singleton baby at the facility.

The exclusion criteria included;

- Twin gestations

- Deliveries of referral cases from other hospitals

\section{Statistical analysis}

Data obtained from the medical records were transferred unto a data capture form, the secondary data was later collated, scrutinized and analysed using IBM Statistical package for Social Sciences (SPSS) version 21. Pearson Chi-square test was used to analyze categorical variables. Relative risk and Odds ratio were used as a measure of the degree of association between an event (outcome) and comparable groups. Students T- test and One way analysis of variance (one-way Anova) were used to analyze the difference in mean values between a set of comparable groups or values. Bonferroni was used as 
the post hoc test after one- way Anova. A $p$-value less than 0.05 was considered statistically significant.

\section{Potential confounders}

The study assumed that antibiotic prescribed was synonymous with exposure which is not always the case. Because of the rural nature of the setting the hospital dispensary dispenses most of the medications prescribed at the same facility. This reduces the inconvenience of patients moving to city centers for their prescribed medicines. The dose prescribed, the duration of therapy and the frequency of administration were not taken into consideration.

The design of the study could not totally account for possible out-of- hospital antibiotic use. The choice of a rural community with few chemical shop outlets and no pharmacy was expected to reduce this potential confounder.

The National Health Insurance Scheme runs a "capitation policy" where a patient chooses one primary health care facility for their needs. The policy also reduces patients moving from one hospital to another because if a patient visits another hospital they have to pay hospital charges. This reduces attrition and tendency for self- medication.

\section{Results}

\section{Sociodemographic data}

The biodata recorded were mothers' age at birth, gravida, marital status, occupational status and religious affiliation. Mothers' age at birth ranged from 13 to 44 years with a mean age of $26.3 \pm 6.40$ years. Most of the pregnant women were between 20 and 30 years, married and average number of gravida of $3.07 \pm 2.03$. (Table 1 ).

\section{Prevalence of antibiotic exposure}

About two out of three women $(65.8 \%, n=271)$ attending ANC clinic in the hospital were treated with an antibiotic at a point during pregnancy. There was no association between the socio-economic status of a woman, i.e., marital status, occupation, age etc. with the odds of being treated with antibiotics. However antibiotic use was associated multiple gravida and Cesarean section. The odds ratio for antibiotic exposure during Caesarean were 13.8 times higher (95\% CI, 5.9-32.5, $\mathrm{K}=55.47)$ than that for women who delivered vaginally.

There was an association $(p<0.001)$ between antibiotic exposure with advance in stage of pregnancy (Fig. 1). Most exposures (79.0\%) were third trimester exposures. In fact $42.4 \%$ all antibiotic treatments occurred within $24 \mathrm{~h}$ to delivery and about $84 \%$ of these women went through Caesarean section. First trimester exposures accounted for just $16.6 \%$. Furthermore $4.40 \%$ women received antibiotics in all three trimesters. Interestingly, 5.5\% went through gestation and Caesarian without receiving any antibiotics at all (Table 2).
Table 1 Socio-demographic characteristics of participants

\begin{tabular}{|c|c|c|c|}
\hline & & Frequency & Percent \\
\hline \multirow[t]{2}{*}{ Marital status } & Married & 304 & 82.2 \\
\hline & Single & 66 & 17.8 \\
\hline \multirow[t]{3}{*}{ Mothers age at birth } & $\geq 19$ & 56 & 13.7 \\
\hline & $20-30$ & 251 & 61.4 \\
\hline & $\leq 31$ & 102 & 24.9 \\
\hline \multirow[t]{9}{*}{ Occupation } & Farmer & 126 & 34.3 \\
\hline & Trader & 78 & 21.3 \\
\hline & Student & 43 & 11.7 \\
\hline & Teacher & 8 & 2.2 \\
\hline & Seamstress & 27 & 7.4 \\
\hline & Hairdresser & 51 & 13.9 \\
\hline & Nurse & 3 & .8 \\
\hline & Unemployed & 27 & 7.4 \\
\hline & Others $^{\mathrm{a}}$ & 4 & 1.0 \\
\hline \multirow[t]{3}{*}{ Religious affiliation } & Christian & 333 & 91.2 \\
\hline & Muslim & 24 & 6.6 \\
\hline & Traditional & 8 & 2.2 \\
\hline \multirow[t]{3}{*}{ GRAVIDA } & $1-3$ & 212 & 68.8 \\
\hline & $\leq 4$ & 96 & 31.2 \\
\hline & Total & 412 & 100.0 \\
\hline
\end{tabular}

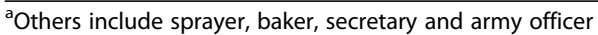

Prevalence of antibiotic use in pregnancy showed a steady increase of $54.8 \%$ in 2013 to a peak of $77.8 \%$ in 2015 .

\section{Classes of antibiotics prescribed}

Beta lactams antibiotics i.e. cephalosporins and penicillins accounted for more than $67 \%$ of antibiotics used whilst metronidazole was used in $24 \%$ of pregnant women. Quinolones and sulphonamide/trimethoprim represented about of $2.1 \%$ antibiotics prescribed. Cephalosporins, penicillins and metronidazole showed a steep rise in use from first trimester to third trimester (Fig. 2). Macrolide use diminished as pregnancy progressed. Use of quinolones and co-trimoxazole however declined to zero in third trimester. $60 \%$ of the patients were given antibiotic because of a urinary tract infection, $12 \%$ due to respiratory tract infections, $14.3 \%$ as premedication for caesarean section. Other minor reasons included gastroenteritis (5.5\%), premature rapture of membranes $(2.8 \%)$, pelvic inflammatory disease (1.7\%) and unspecified indications (3.7\%).

\section{Safety and appropriateness in pregnancy}

The FDA classifications for the drugs prescribed in the study fell into classes B, C and D with classes A and X antibiotic not prescribed. Most of the drugs fell into category B with $96.6 \%$ followed by C and D with $2.9 \%$ and $0.5 \%$ respectively. It was observed that some antibiotics were prescribed without due justification i.e. there 


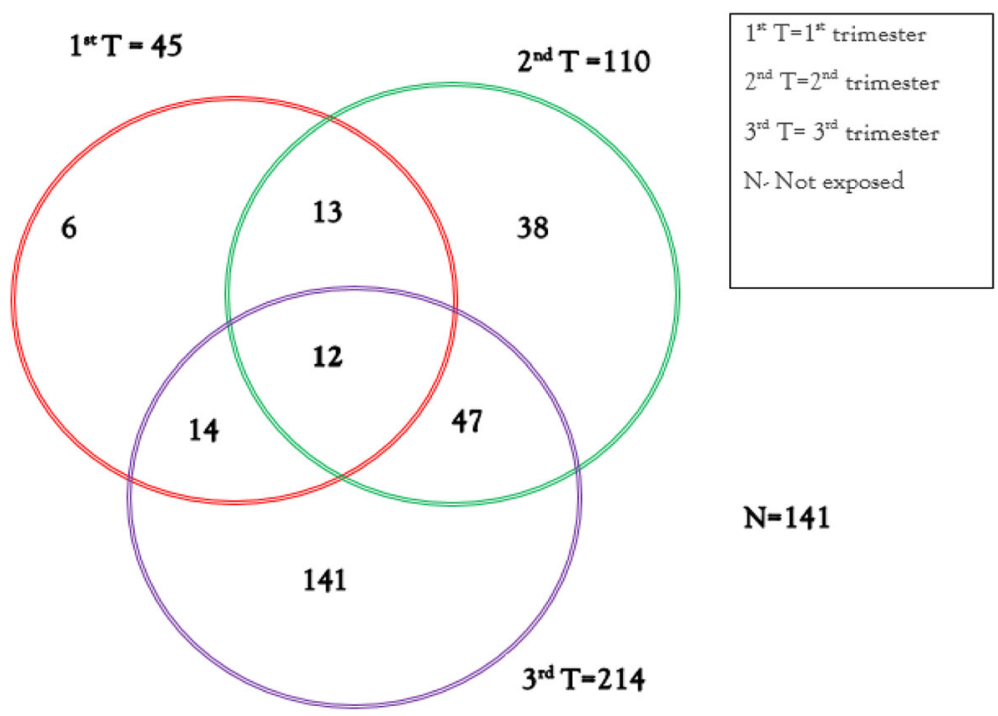

Fig. 1 Antibiotic use during pregnancy during the different stages of pregnancy. 12 respondents received antibiotics at all stages of pregnancy. 141 did not received antibiotics at all. 13 received during the 1 st and 2 nd trimesters only. 47 received antibiotics during the 2 nd and 3 rd trimesters only. 14 respondents received during the 1 st and 3rd trimesters only. 141 respondents were treated during the 3rd trimester

was drug -diagnosis mismatch and this constituted 3.5\% of all prescriptions issued.

\section{Intrapartum antibiotic exposure and birth outcomes Antibiotic exposure and birthweight}

The mean birthweight of babies who delivered at the facility was $2.96 \pm 0.56 \mathrm{~kg}$. Intrapartum antibiotic treatment did not affect mean birthweight. Similarly there was no statistically significant relationship between mode of delivery and birthweight. Generally, there was a direct relationship between mothers' socio-economic status and birthweight. Babies born of single mothers had lower birthweights compared to those born of married mothers $(p<0.001, \mathrm{~F}=12.74)$ (Table 3$)$.

\section{Antibiotic exposure and Apgar scores}

There was no statistically significant relationship between antibiotic prescription during pregnancy and

Table 2 Antibiotic exposure in pregnant women of different socio economic class and mode of delivery

\begin{tabular}{|c|c|c|c|c|c|}
\hline \multicolumn{6}{|l|}{ Antibiotic exposure } \\
\hline & & Yes & No Total & & Statistics \\
\hline \multirow[t]{2}{*}{ Marital status } & Married & 197(64.8\%) & 107(35.2\%) & 304 & $P=0.77, \mathrm{DF}=1$ \\
\hline & Single & $44(66.7 \%)$ & $22(33.3 \%)$ & 66 & $k=0.83, O R=0.97$ \\
\hline \multirow[t]{3}{*}{ Age of mother at birth } & $\geq 19$ & $32(57.1 \%)$ & $24(43.9 \%)$ & 43 & $P=0.357, \mathrm{DF}=2$ \\
\hline & $20-30$ & $167(66.5 \%)$ & $8(33.5 \%)$ & 238 & $K=2.058$ \\
\hline & $\leq 31$ & $69(67.6 \%)$ & $33(32.4 \%)$ & 96 & \\
\hline \multirow[t]{3}{*}{ Occupation } & Employed & $182(64.6 \%)$ & 105(37.4\%) & 126 & $P=0.61, K=10.06$ \\
\hline & Student & $27(62.8 \%)$ & $16(37.2 \%)$ & 43 & \\
\hline & Unemployed & 19(70.4\%) & $8(29.6 \%)$ & 27 & \\
\hline \multirow[t]{3}{*}{ Religion } & Christian & $219(65.8 \%)$ & $114(34.2 \%)$ & 333 & $P=0.368, K=1.99$ \\
\hline & Muslim & $15(62.5 \%)$ & $9(37.5 \%)$ & 24 & $\mathrm{DF}=2$ \\
\hline & Traditional & $5(62.5 \%)$ & $3(37.5 \%)$ & 8 & \\
\hline \multirow[t]{2}{*}{ GRAVIDA } & $1-3$ & $117(60.9 \%$ & 75(39.1\%) & 192 & $P=0.066, \mathrm{~K}=3.38$ \\
\hline & $\leq 4$ & $67(72.0 \%)$ & $26(28.0 \%)$ & 93 & $\mathrm{DF}=1 \mathrm{OR}=0.83$ \\
\hline \multirow[t]{2}{*}{ Method of delivery } & C. SectioN & 104(94.5\%) & $6(5.5 \%)$ & 110 & $P<\mathbf{0 . 0 0 1}, \mathrm{K}=55.47$ \\
\hline & Vaginal & $167(55.3 \%)$ & $135(44.7 \%)$ & 302 & $\mathrm{DF}=1 \mathrm{OR}=13.8$ \\
\hline Total & & $271(65.8 \%)$ & $141(34.2 \%)$ & 412 & \\
\hline
\end{tabular}




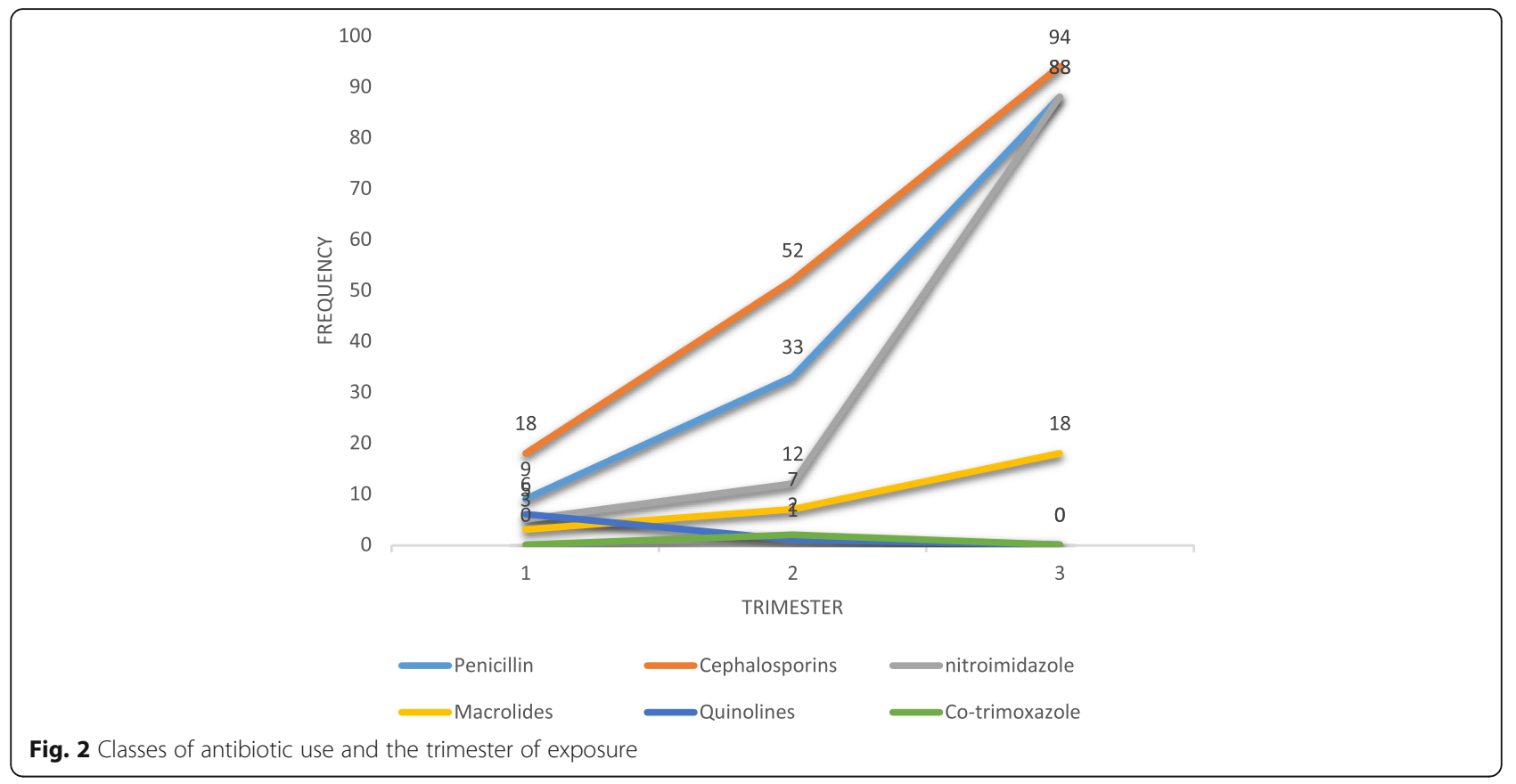

mean Apgar scores (i.e. $8.242 \pm 1.3$ vs $8.32 \pm 1.62$ $(p=0.414, \mathrm{~F}=1.59))$. However when mothers were treated with antibiotics in less than $24 \mathrm{~h}$ to parturition, there was a statistically significant decrease in mean Apgar than those not treated with antibiotics i.e. $(7.86 \pm 1.72$ vs $8.4 \pm 1.30 p=0.002, \mathrm{~F}=13.65)$ after adjusting for the effects of the mode of delivery.

Table 3 Effect intrapartum antibiotic exposure on weight at birth

\begin{tabular}{|c|c|c|c|}
\hline & \multicolumn{3}{|l|}{ Birth Weight } \\
\hline & & $\mathrm{N}$ & Mean \pm SD \\
\hline \multirow[t]{2}{*}{ Marital status } & Married & 298 & $3.02 \pm 0.56^{* * *}$ \\
\hline & Single & 65 & $2.75 \pm 0.53$ \\
\hline \multirow[t]{3}{*}{ Age group } & $\geq 19$ & 55 & $2.75 \pm 0.48^{* * *}$ \\
\hline & $20-30$ & 242 & $2.95 \pm 056$ \\
\hline & $\leq 31$ & 100 & $3.10 \pm 0.57$ \\
\hline \multirow[t]{3}{*}{ Occupational status } & Employed & 287 & $3.00 \pm 0.57^{*}$ \\
\hline & Student & 43 & $2.75 \pm 0.58$ \\
\hline & Unemployed & 27 & $3.00 \pm 0.47$ \\
\hline \multirow[t]{3}{*}{ Religion } & Christian & 324 & $2.98 \pm 0.57$ \\
\hline & Muslim & 23 & $2.82 \pm 0.48$ \\
\hline & Traditional & 8 & $2.88 \pm 0.52$ \\
\hline \multirow[t]{2}{*}{ GRAVIDA } & $1-3$ & 206 & $2.87 \pm 0.51^{* * *}$ \\
\hline & 4 And Above & 95 & $3.08 \pm 0.57$ \\
\hline \multirow[t]{2}{*}{ Mode of delivery } & Ceasarian section & 103 & $2.96 \pm 0.59$ \\
\hline & Vaginal delivery & 297 & $2.96 \pm 0.55$ \\
\hline \multirow[t]{2}{*}{ Antibiotic exposure } & Yes & 261 & $2.96 \pm 0.58$ \\
\hline & No & 139 & $2.97 \pm 0.53$ \\
\hline
\end{tabular}

Results represented as mean \pm SD. ${ }^{*}$ means $p<0.05,{ }^{* * *} p<0.001$
Babies born naturally had mean Apgar scores statistically higher than those born by Caesarean section i.e. $8.42 \pm 1.23$ vs $7.86 \pm 1.87(p=0.003, \mathrm{~F}=8.98)$. Younger mothers, unmarried women and mothers with less gravida had significantly higher mean Apgar scores compared with older $(p=0.046)$, married $(p=0.018)$ and higher gravida $(p=0.034)$ mothers respectively (Table 4 ).

\section{Antibiotic exposure and congenital birth defect}

Six birth defects were seen in the study representing $1.5 \%$ of all deliveries i.e. Cleft lip, mega cephalous, cleft palate and webbed feet. Intrapartum antibiotic exposure irrespective of trimester of exposure was not associated with any significant risk of birth defect $(R R=1$, $P=0.97)$. There was no statistically significant association between marital status $(p=0.94)$, mothers age at birth $(p=0.361)$, occupation $(p=0.630)$, parity $(p=0.94)$ and religion $(p=0.49)$ and birth defects. Females had relatively higher odds ratio of incidence of birth defects than males. i.e. $2.2 \%$ vs $1.0 \%(\mathrm{OR}=2.2$, $P=0.343,95 \% \mathrm{CI})$.

\section{Discussion}

The study was design to ascertain the prevalence antibiotic prescription among pregnant women attending ANC. About $65.8 \%$ of pregnant women were exposed to an antibiotic at some point during pregnancy. This figure was higher than an earlier report of about by $59.9 \%$ in the eastern region of Ghana [10] as well as the WHO/International Network for the Rational Use of Drugs figures. Women who went through Caesarean 
Table 4 Effect intrapartum antibiotic exposure on mean APGAR score

APGAR Scores

\begin{tabular}{|c|c|c|c|}
\hline & & $\mathbf{N}$ & Mean \pm SD \\
\hline \multirow[t]{2}{*}{ Marital status } & Married & 282 & $8.26 \pm 1.37^{*}$ \\
\hline & Single & 62 & $8.69 \pm 0.90$ \\
\hline \multirow[t]{3}{*}{ Age groups } & $\leq 19$ & 53 & $8.60 \pm 1.10^{*}$ \\
\hline & $20-30$ & 232 & $8.41 \pm 1.28$ \\
\hline & $\geq 31$ & 93 & $8.10 \pm 1.43$ \\
\hline \multirow[t]{3}{*}{ Occupational status } & Employed & 272 & $8.32 \pm 1.32$ \\
\hline & Student & 41 & $8.40 \pm 1.25$ \\
\hline & Unemployed & 25 & $8.48 \pm 0.95$ \\
\hline \multirow[t]{3}{*}{ Religion } & Christian & 311 & $8.33 \pm 1.34$ \\
\hline & Muslim & 21 & $8.43 \pm 1.15$ \\
\hline & Traditional & 1 & $9.00 \pm 0.00$ \\
\hline \multirow[t]{2}{*}{ GRAVIDA } & $1-3$ & 200 & $8.54 \pm 1.22^{*}$ \\
\hline & $\geq 4$ & 88 & $8.20 \pm 1.27$ \\
\hline \multirow[t]{2}{*}{ Mode of delivery } & Ceasarian section & 100 & $8.03 \pm 1.67^{* *}$ \\
\hline & Vaginal delivery & 281 & $8.47 \pm 1.11$ \\
\hline \multirow[t]{2}{*}{ Antibiotic exposure } & Yes & 248 & $8.30 \pm 1.30$ \\
\hline & No & 133 & $8.47 \pm 1.26$ \\
\hline \multirow[t]{2}{*}{ Perinatal antibiotic exposure } & Yes & 104 & $7.96 \pm 1.70^{* *}$ \\
\hline & No & 277 & $8.51 \pm 1.07$ \\
\hline
\end{tabular}

Results represented as mean \pm SD. ${ }^{*}$ means $p<0.05,{ }^{* *} p<0.01$

section were more likely to receive antibiotics to control wound infection and endometritis $[11,12]$.

Risk of antibiotic exposure was highest in the last trimester but it corresponded with the increased incidence of respiratory tract infections, urinary tract infections and gastritis during third trimester. This is of a concern because acquisition of specific foetal immunity begins in the third trimester and it is highly dependent on microbiome which can be altered by antibiotics $[9,13]$.

Most of the antibiotic used are classified as safe in pregnancy by the FDA. Macrolides though safe, directly stimulate the motilin receptors inducing Gastro-intestinal discomfort which may be undesirable in pregnancy $[14,15]$. Anatomically the uterus sits directly on the urinary bladder and so increase in weight of the uterus as pregnancy advances exerts a proportional pressure on the bladder and stomach leading to increased incidence of UTI, gastritis and heartburns [16, 17].

Babies exposed to intrapartum antibiotics had mean weights slightly lower than those unexposed. A study by Vidal et al., (2013) [8] reported a similar pattern and it was further observed that such babies quickly gained much more weight after delivery leading to obesity in childhood. This study also noted a strong association between mother's socio-economic factors and birthweights as has been reported elsewhere [18-20]. This may be due to economic stability, marital support etc [18, 21, 22]. Babies born to Mothers who received antibiotics less than $24 \mathrm{~h}$ to delivery or subsequently had caesarean birth had lower mean Apgar scores much even after adjusting for other confounding factors. This correlates with other reports in which babies born vaginally had much higher Apgar scores at 5 min compared to caesarean born [23]. Older mothers or women with higher gravida had babies with mean Apgar scores lower than younger mothers or women with less gravida.

A total six birth defects (15 per 10,000 live births) were recorded in this study. This figure was similar to other prevalence birth defects reported other authors [24].

\section{Conclusion}

$65 \%$ of pregnant women received antibiotics at some stage during pregnancy. Antibiotic use did not affect mean birth weight, APGAR score or incidence of birth defects. However, antibiotic use less than $24 \mathrm{~h}$ to delivery was associated with a decrease in mean APGAR score.

\section{Abbreviations}

ANC: Ante natal clinic; APGAR: Appearance, pulse, grimace, activity and respiration; FDA: Food and drugs authority; RR: Relative risk; SDA: Seventhday adventist

\section{Acknowledgements}

The authors would like to acknowledge the help and assistance of Staff at Gynecological unit of SDA hospital, Dominase, Ashanti Region.

\section{Ethics approval and consent for participate}

The permission to do this research in Seventh-Day Adventist Hospital, Dominase was approved by the hospital management committee Ethical Ref NO: RD01/ 16. Permission from individuals was not feasible since the primary source of data was medical records of patients filed in the hospital. Patients' names were excluded in the data collection to protect patient confidentiality. Ethical clearance was given by the Committee on Human Research, Publications and Ethics, Kwame Nkrumah University of Science And Technology, School of Medical Sciences and Komfo Anokye Teaching Hospital, KUMASI. Ethical Ref NO: CHRPE/AP/347/16.

Funding

Authors did not get funding for this project. Authors paid for the cost the project.

Availability of data and materials

Personal data from this study will not be shared publicly for ethical reasons.

\section{Authors' contributions}

$\mathrm{KOA}, \mathrm{KBM}$ and CA participated in the conception and design of the manuscript. KOA, KBM performed the statistical analysis and drafted the manuscript. All authors read and approved the final manuscript.

\section{Consent for publication}

Not applicable in this study.

Competing interests

Authors have no competing interest.

\section{Publisher's Note}

Springer Nature remains neutral with regard to jurisdictional claims in published maps and institutional affiliations. 
Received: 25 February 2017 Accepted: 20 July 2017

Published online: 09 August 2017

\section{References}

1. Van Boeckel TP, Gandra S, Ashok A, Caudron Q, Grenfell BT, Levin SA, Laxminarayan R. Global antibiotic consumption 2000 to 2010: an analysis of national pharmaceutical sales data. Lancet Infect Dis. 2014;14:742-50.

2. Kalliomäki M, Collado MC, Salminen S, Isolauri E. Early differences in fecal microbiota composition in children may predict overweight. Am J Clin Nutr. 2008;87(3):534-8.

3. United Nations. The millennium development goals report 2014. New York: United Nations; 2014.

4. World Health Organization, Unicef. "Trends in maternal mortality: 1990 to 2013: estimates by WHO, UNICEF, UNFPA, the World Bank and the United Nations population division:" 2014.

5. de Tejada BM. Antibiotic use and misuse during pregnancy and delivery: benefits and risks. Int J Environ Res Public Health. 2014;11(8): 7993-8009.

6. Kim MA, Yee NH, Choi JS, Choi JY, Seo K. Prevalence of birth defects in Korean livebirths, 2005-2006. J Korean Med Sci. 2012;27(10):1233-40.

7. Crider KS, Cleves MA, Reefhuis J, Berry RJ, Hobbs CA, Hu DJ. Antibacterial medication use during pregnancy and risk of birth defects: National Birth Defects Prevention Study. Arch Pediatr Adolesc Med. 2009;163(11):978-85.

8. Vidal AC, Murphy SK, Murtha AP, Schildkraut JM, Soubry A, Huang Z, Neelon SB, Fuemmeler B, Iversen E, Wang F, Kurtzberg J. Associations between antibiotic exposure during pregnancy, birth weight and aberrant methylation at imprinted genes among offspring. Int J Obes. 2013;37(7):907-13.

9. Mensah KB, Ansah C. Irrational use of antibiotics and the risk of diabetes in Ghana. Ghana Med J. 2016;50(2):107-14.

10. Ahiabu MA, Tersbøl BP, Biritwum R, Bygbjerg IC, Magnussen P. A retrospective audit of antibiotic prescriptions in primary health-care facilities in eastern region, Ghana. Health Policy Plan. 2015;4:czv048.

11. Smaill FM, Grivell RM. Antibiotic prophylaxis versus no prophylaxis for preventing infection after cesarean section. Cochrane Data Syst Rev. 2014;10:CD007482

12. Costantine MM, Rahman M, Ghulmiyah L, Byers BD, Longo M, Wen $T$, Hankins GD, Saade GR. Timing of perioperative antibiotics for cesarean delivery: a metaanalysis. Am J Obstet Gynecol. 2008;199(3):301-e1.

13. Prescott SL, Clifton V. Asthma and pregnancy: emerging evidence of epigenetic interactions in utero. Curr Opin Allergy Clin Immunol. 2009;1:9(5):417-26.

14. Weber FH Jr, Richards RD, McCallum RW. Erythromycin: a motilin agonist and gastrointestinal prokinetic agent. Am J Gastroenterol. 1993;88(4):1.

15. Periti P, Mazzei T, Mini E, Novelli A. Adverse effects of macrolide antibacterials. Drug Saf. 1993;1:9(5):346-64.

16. Masinde A, Gumodoka B, Kilonzo A, Mshana SE. Prevalence of urinary tract infection among pregnant women at Bugando medical Centre, Mwanza, Tanzania. Tanzan J Health Res. 2009;11(3).

17. Köksal Ö, Özdemir F, Armağan E, Öner N, Sert PÇ, Sigirli D. Is routine pregnancy test necessary in women of reproductive age admitted to the emergency department? World J Emerg Med. 2013;4(3):175.

18. Bhaskar RK, Deo KK, Neupane U, Chaudhary Bhaskar S, Yadav BK, Pokharel HP, Pokharel PK. A case control study on risk factors associated with low birth weight babies in eastern Nepal. Inter J Pediat. 2015;10:2015.

19. Brotnow L, Reiss D, Stover CS, Ganiban J, Leve LD, Neiderhiser JM, Shaw DS, Stevens HE. Expectant mothers maximizing opportunities: maternal characteristics moderate multifactorial prenatal stress in the prediction of birth weight in a sample of children adopted at birth. PLoS One. 2015 10(11):e0141881.

20. Xaverius P, Alman C, Holtz L, Yarber L. Risk factors associated with very low birth weight in a large urban area, stratified by adequacy of prenatal care. Mater Child Health J. 2016;20(3):623-9.

21. Rondo PH, Ferreira RF, Nogueira F, Ribeiro MC, Lobert H, Artes R. Maternal psychological stress and distress as predictors of low birth weight, prematurity and intrauterine growth retardation. Eur J Clin Nutr. 2003;57(2):266-72

22. Bodin L, Axelsson G, Ahlborg G Jr. The association of shift work and nitrous oxide exposure in pregnancy with birth weight and gestational age. Epidemiology. 1999;10(4):429-36.
23. Burt RD, Vaughan TL, Daling JR. Evaluating the risks of cesarean section: low Apgar score in repeat C-section and vaginal deliveries. Am J Public Health. 1988;78(10):1312-4.

24. Zaganjor I, Sekkarie A, Tsang BL, Williams J, Razzaghi H, Mulinare J, Sniezek $J E$, Cannon MJ, Rosenthal J. Describing the global burden of neural tube defects: A systematic literature review. In Birth defects research Part AClinical and molecular teratology. 103 NJ: Wiley; 2015. p. 418.

\section{Submit your next manuscript to BioMed Central and we will help you at every step:}

- We accept pre-submission inquiries

- Our selector tool helps you to find the most relevant journal

- We provide round the clock customer support

- Convenient online submission

- Thorough peer review

- Inclusion in PubMed and all major indexing services

- Maximum visibility for your research

Submit your manuscript at www.biomedcentral.com/submit
) Biomed Central 